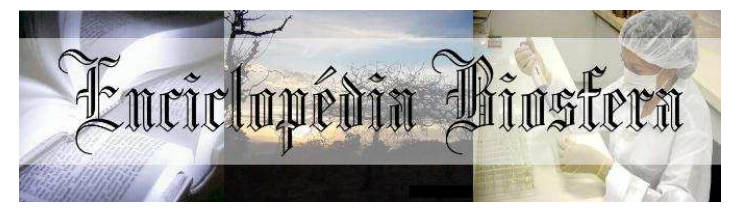

\title{
IMPACTOS DAS EVOLUÇÕES DEMOGRÁFICA E ECONÔMICA NA DEMANDA LOCAL POR CARNE DE FRANGO: O EXEMPLO DE JUAZEIRO DO NORTE - CEARÁ
}

Fabiano da Silva Ferreira ${ }^{1}$; Pedro Bruno Xavier Alcântara²; Brendo Alves da Silva²; Emábile Sampaio de Carvalho ${ }^{3}$; Ítalo Bruno Bezerra Mota ${ }^{2}$

${ }^{1}$ Professor da Universidade Federal do Cariri-UFCA, Crato. Brasil. E-mail: fabiano.ferreira@ufca.edu.br

${ }^{2}$ Graduando do curso de Agronomia da Universidade Federal do Cariri - UFCA

${ }^{3}$ Engenheira agrônoma pela Universidade Federal do Cariri - UFCA

Recebido em: 02/10/2017 - Aprovado em: 21/11/2017 - Publicado em: 05/12/2017 DOI: 10.18677/EnciBio_2017B24

\begin{abstract}
Apesar da dinâmica da demanda pela carne de frango ser decorrente de uma série de fatores, percebe-se que a procura por esse alimento parece estar mais relacionada com o fator renda. A presente pesquisa objetivou analisar os impactos que o crescimento demográfico e a recente e forte evolução econômica pela qual passou a cidade cearense de Juazeiro do Norte, pode causar na demanda local por carne de frango, caso o referido crescimento venha a ocorrer novamente na cidade. Com base nas taxas de crescimento populacional e da renda per capita, calculadas a partir de séries históricas do período 2002-2014, bem como na elasticidade-renda da demanda de frango constante na literatura, projeções foram feitas para a procura local por frango. Verifica-se, que a demanda local tenderia a crescer a um ritmo médio de $8,3 \%$ ao ano, se tanto a população como a renda per capita média local, mantivesse o crescimento constantado no período considerado. Projetando-se para o quinquênio 2018-2022, a demanda por frango aumentará quase $50 \%$ e esse signifcativo incremento de consumo colocará a produção de frango na liderança das atividades com mais impacto na geração de renda local, pela importância que o consumo desse alimento tem hoje nas famílias brasileiras.
\end{abstract}

RESUMO

PALAVRAS-CHAVE: Cariri, consumo de frango, taxa de crescimento.

\section{IMPACTS OF DEMOGRAPHIC AND ECONOMIC DEVELOPMENTS IN LOCAL DEMAND FOR CHICKEN MEAT: THE EXAMPLE OF JUAZEIRO DO NORTE- CEARÁ}

\begin{abstract}
Although the dynamics of the demand for chicken meat is due to a series of factors, it is perceived that the demand for this food appears to be more related to the income factor. The present study aimed to analyze the impacts that the population growth and the recent and strong economic evolution that the city of Juazeiro do Norte experienced in the city may cause local demand for chicken meat if this growth
\end{abstract}


occurs again in the city. Based on population growth rates and per capita income, calculated from the historical series of the period 2002-2014, as well as the income elasticity of constant chicken demand in the literature, projections were made for local demand for chicken. It is verified that local demand would tend to grow at an average rate of $8.3 \%$ per year if both the population and the local average per capita income maintained the growth constant during the period considered. Projecting for the 2018-2022 quinquennium, the demand for chicken will increase almost $50 \%$ and this significant increase in consumption will put chicken production one of the activities with more impact on local income generation, given the importance of the consumption of this food today In Brazilian families.

KEYWORDS: Poultry farming; Cariri; Food consumption; Growth rate

\section{INTRODUÇÃO}

Apesar da dinâmica da demanda pela carne de frango ser decorrente de uma série de fatores como o crescimento econômico e o perfil da população de cada local, a geração de postos de trabalho, os padrões de vida existentes, os valores dentre outros, percebe-se que a procura por esse alimento encontra-se intrinsecamente mais relacionada com o fator renda. Até meados do final de 2014, ou seja, antes da atual crise pelo qual passa o Brasil, a ascensão econômica de cidades como Juazeiro do Norte, no sul do Estado do Ceará, vinha gerando ótimas oportunidades de trabalho e de renda em todos os setores da economia e em alguns novos nichos de mercado (QUEIROZ, 2014).

Historicamente, segundo Queiroz (2014), desde a década de 1960, a cidade de Juazeiro do Norte já despontava como o maior empório comercial da região do Cariri cearense, esta localizada no sul do Estado do Ceará e abrangendo cerca de 30 municípios. Nesse contexto, constata-se que essa característica local tem acarretado importantes mudanças socioespaciais no município, visto que do ano de 1991 a 2010 a população passou de 173.566 para 261.089, segundo dados do Instituto Brasileiro de Geografia e Estatística - (IBGE, 2017), significando um aumento demográfico de 50,4\%, implicando, assim, na geração cada vez maior dos mais variados tipos de demandas socioeconômicas locais.

Dados divulgados em IBGE (2017) revelam um crescimento econômico relevante em Juazeiro do Norte de 1999 a 2012, onde houve um aumento de $459,1 \%$ no Produto Interno Bruto, com os valores (não corrigidos) da renda per capita passando de $R \$ 3.041,00$ em 2002 para $R \$ 7.842,00$ em 2010, correspondendo a um aumento de 158\%. Sabe-se que avanços dessa natureza geram importantes reflexos sobre a economia local, interferindo diretamente sobre a demanda e a oferta dos mais variados tipos de produtos, ainda mais quando fenômenos dessa natureza ocorrem concomitantemente com a busca cada vez maior da população, por uma melhor qualidade de vida a partir do consumo de alimentos mais saudáveis, mais práticos e mais acessíveis. Nesse caso, é realmente de se esperar que o aumento da renda per capita tenda a elevar a demanda agregada também por alimentos de origem animal, como as carnes.

Esse fato foi anteriormente enfatizado por Carbonari e Silva (2012), ao relatarem que dos $89,2 \mathrm{~kg}$ anuais de carne consumidos por pessoa no Brasil, 38,9 $\mathrm{kg}$ são de carne de frango. Entretanto, dados da Companhia Nacional de Abastecimento - CONAB informam que em 2017 a oferta no mercado interno desse alimento deve resultar em 42,8 quilos por habitante/ano (GLOBO RURAL, 2017) e projeções do Ministério da Agricultura Pecuária e Abastecimento (MAPA, 2017) 
mostram um crescimento de $2,8 \%$ ao ano na produção de frango, entre os anos de 2016 e 2027, com o consumo de carne de frango passando para 54,3 kg/hab/ano.

Diante disso, a partir de projeções realizadas com a utilização de séries históricas, a presente pesquisa objetivou analisar os impactos que o crescimento demográfico e a recente e forte evolução econômica pela qual passou a cidade cearense de Juazeiro do Norte pode causar na demanda local por carne de frango, caso o referido crescimento venha a ocorrer novamente na cidade.

\section{MATERIAL E MÉTODOS}

A pesquisa abrangeu o município de Juazeiro do Norte, localizado ao sul do Estado do Ceará. Com uma população estimada de 268.248 habitantes em 2016 (IBGE, 2017), é uma cidade situada em um ponto estratégico na região Nordeste, por estar a distâncias semelhantes de importantes capitais nordestinas, Fortaleza (500 km), Recife (605 km), Natal (625 km) e João Pessoa (621 km) (Figura 1).

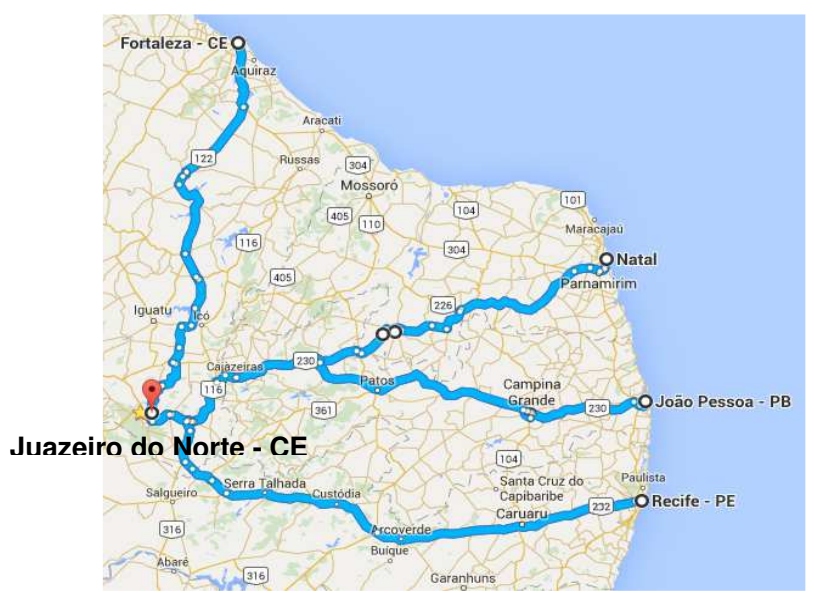

FIGURA 1 - Equidistâncias entre Juazeiro do Norte - CE e algumas capitais do Nordeste do Brasil.

Fonte: Elaboração própria

Para a realização da pesquisa, foi utilizada de início a equação abaixo:

Onde:

$$
D=P+E G
$$

$D=$ taxa de crescimento da demanda por carne de frango para a cidade de Juazeiro do Norte;

$P=$ taxa de crescimento demográfico da cidade de Juazeiro do Norte;

$E=$ coeficiente de elasticidade-renda do frango;

$G=$ taxa de crescimento da renda per capita da cidade de Juazeiro do Norte.

Conforme Hoffmann (1992), a fórmula acima possibilita, com base nas taxas de crescimento da população e da renda per capita de determinado lugar e com a elasticidade-renda da demanda de certo produto, se fazer projeções de demanda por esse produto e para certo local (cidade, Estado etc.) para qualquer período de tempo. Para ser possível a utilização da equação 1, foram utilizados dados anuais da população e do Produto Interno Bruto (PIB) da cidade de Juazeiro do Norte, 
obtidos diretamente do site do Instituto Brasileiro de Geografia e Estatística - IBGE, no período compreendido entre os anos 2002 e 2014.

Em seguida, após a obtenção da renda per capita a partir da divisão dos valores anuais do PIB pela população, as taxas de crescimento demográfico $(P)$ e da renda per capita $(G)$ foram obtidas por regressão linear simples, detalhado em Hoffmann (1992). Conforme essa metodologia, com os valores anuais de população e de renda per capita, foi possível analisar o mais precisamente, o comportamento evolutivo dessas grandezas entre os anos de 2002 e 2014, a partir das suas taxas de crescimento.

O período delimitado é justificado pela disponibilidade dos dados no site do IBGE. A análise com a referida regressão, como descreve Hoffmann (2015), possibilitou relacionar as variáveis por meio de uma expressão matemática, a partir da qual podia se estimar valores de uma das variáveis com os valores das outras variáveis. Com os dados da tabela ANOVA, obtida pelo software Excel, determinouse as taxas de crescimento a partir dos valores do parâmetro $\underline{b}$ estimado, da equação linear $Y=a+b X$, sendo esta, obtida da aplicação de logaritmos na expressão $V_{t}=A(1+r)^{t}$, que possibilita, conforme Hoffmann (1992), determinar a taxa geométrica de crescimento $r$ de uma grandeza no período de $t$ anos.

Quanto ao coeficiente de elasticidade-renda da demanda $(E)$, foi realizada uma busca junto à literatura, até se chegar em estudos que oferecessem valores correspondentes à carne de frango. Trata-se de um indicador que, como afirma Varian (2016), descreve como a quantidade demandada reage à variação na renda. Nesse caso, pode ser uma ferramenta utilizada para relacionar o crescimento econômico, medido pelo Produto Interno Bruto (PIB) com a demanda pelo produto.

Foram utilizados os coeficientes obtidos por Silveira et al. (2007), para as Regiões Metropolitana de Fortaleza e de Recife, que são bastante próximos e assim, por ambos representarem a mesma característica quanto à sensibilidade do produto com relação à renda das pessoas, calculou-se a média entre os dois como forma de obter um valor que contemple as características de consumo e de renda da cidade de Juazeiro do Norte, considerando a sua posição equidistante para as duas referidas capitais. Depois de determinados os valores da taxa de crescimento da demanda, a partir da equação (1), foram feitas projeções para a demanda por carne de frango para Juazeiro do Norte para o quinquênio 2018-2022.

\section{RESULTADOS E DISCUSSÃO}

\section{Quanto à evolução demográfica de Juazeiro do Norte}

Hoffmann (1992) considera que a população de um país normalmente cresce segundo uma função exponencial, sendo sua taxa de crescimento relativamente constante, quando os fatores que normalmente influenciam na variação demográfica, mantêm comportamentos semelhantes ao verificado entre o período considerado.

Verifica-se que a população da cidade de Juazeiro do Norte aumentou a uma taxa média anual de $1,5 \%$ durante os doze anos analisados, passando de 220,2 milhões em 2002 para mais de 263,7 milhões de habitantes em 2014, totalizando um acréscimo de quase 44 mil pessoas durante o referido período, o equivalente a quase $20 \%$ a mais do que o registrado em 2002, correspondendo assim à chegada de 3,6 mil pessoas a cada ano na cidade (Figura 1). 


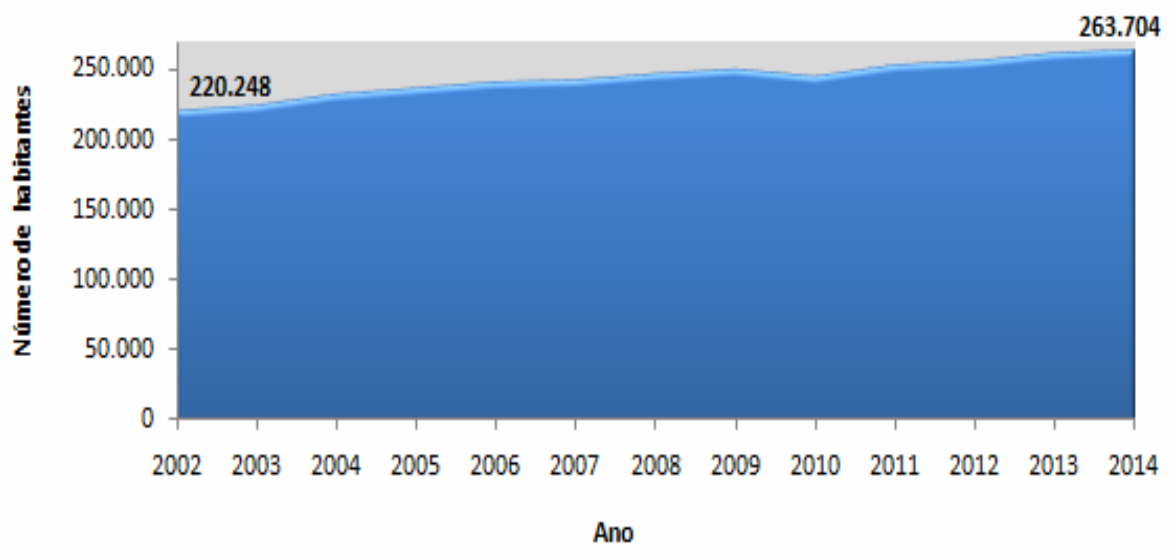

FIGURA 1 - Evolução demográfica da cidade de Juazeiro do Norte - CE. Fonte: Elaboração própria

No presente caso, grande parte desse expressivo aumento populacional devese à significativa fase de crescimento econômico pelo qual passou o referido município, onde se verificavam (e alguns ainda são verificados) investimentos dos mais variados, como nas áreas de saúde (com a instalação de diversas clínicas particulares), educação (com a construção de instituições de ensino superior) e moradia, ocasionando o aumento da demanda por mão de obra e, consequentemente, atraindo mais habitantes para a cidade e municípios vizinhos.

Queiroz (2014) também enfatiza isso, quando afirma que o novo quadro que começou a se desenhar na área da Região Metropolitana do Cariri, mais precisamente em Juazeiro do Norte, a partir da segunda metade dos anos 2000, evidencia um novo estágio do processo de urbanização desta cidade, descolado da dinâmica precedente, não mais vinculado diretamente ao processo de industrialização. Ainda segundo o autor, o estágio atual da dinâmica urbana na Região Metropolitana do Cariri, em muito se assemelha à dinâmica das metrópoles contemporâneas, destacando que esse momento, aliás, foi objeto de uma publicação na Revista Exame de agosto de 2012 que, já na chamada de capa, colocava Juazeiro do Norte em destacada posição entre "as 100 cidades onde o consumo mais crescia" no país.

Como consequência, presume-se que esse comportamento demográfico tende a possibilitar, principalmente em condições de crescimento econômico, a geração de mais emprego e, consequentemente, maior demanda por bens e serviços, dentre estes, por alimentos de forma geral. O fato da referida cidade estar inserida em uma região metropolitana, caracterizada atualmente como um significativo polo econômico regional e ter o aumento constatado no Índice de Desenvolvimento Humano - IDH (IPECE, 2015), passando de 0,596 em 1991 para 0,694 em 2010, também pode explicar essa evolução demográfica.

Outro aspecto importante a ser levado em consideração, é o fato de que a inserção deste contingente populacional juntamente com a emergência do seu poder de aquisição gera uma demanda crescente por itens essenciais, dentre eles, a carne de frango, por ser uma boa alternativa para suprimento de demandas nutricionais e por ter apresentado preços e ofertas cada vez mais acessíveis para a população de um modo geral. Esse crescimento da população local tende a ocasionar uma pressão cada vez maior no abastecimento local de frango e, consequentemente, na produção dessa carne. 
Dados do Ministério da Agricultura e da Pecuária estimam um aumento anual de $3,1 \%$ na produção de carne frango até 2024 , valor superior ao previsto para as carnes suína e bovina, que devem crescer no mesmo intervalo, de 2,8 e 1,9\% ao ano, respectivamente. Ou seja, é notória a relevância cada vez maior da avicultura na alimentação humana e cidades com forte evolução econômica tendem a gerar impactos mais significativos nesse mercado de aves, pela crescente necessidade de consumo e melhor poder de compra dos consumidores.

Essa evolução econômica municipal de Juazeiro do Norte se encaixa na avaliação de Miranda e Gomes Júnior (2017), ao afirmarem que entre 1990 a 2010, observou-se de um lado, os grandes centros urbanos se saturando de gente e atividades e as cidades médias crescendo quantitativamente e ganhando destaque nas regiões metropolitanas brasileiras; e de outro, a emergência de pequenas e médias cidades nas áreas de expansão da fronteira agrícola vão modificando as relações interurbanas, por meio do surgimento de novas centralidades urbanas.

Para Juazeiro do Norte, veículos locais de comunicação (DIÁRIO DO NORDESTE, 2011) indicaram que essa imigração era justificada pela atração que o progresso local estava exercendo como novo polo de desenvolvimento do Nordeste, sendo até então o terceiro maior polo da indústria calçadista brasileira, atrás somente de Franca-SP e de Novo Hamburgo-RS; o terceiro maior polo joalheiro (perdendo apenas para Limeira-SP e Guaporé-RS) e o principal portão de entrada no Nordeste central do Brasil a partir do Aeroporto Regional do Cariri. Além disso, a referida fonte ainda apontou Juazeiro do Norte como o maior centro comercial de automóveis e de motos do interior do Ceará; cidade que mais crescia em educação universitária no interior do Nordeste, mais dinâmico centro da construção civil no interior do Nordeste, ao ritmo de $20 \%$, mais do que o dobro do Brasil; maior centro do artesanato brasileiro e capital brasileira da Literatura de Cordel, além do seu progresso extraordinário como principal centro do catolicismo popular da América Latina, recebendo 2,5 milhões de visitantes ao ano, graças à força carismática do Padre Cícero. Trata-se, portanto, de uma região do Brasil, que assim como muitas outras, apresenta um potencial considerável como mercado consumidor e que responde em termos de evolução demográfica tão logo determinados fatores econômicos começam a favorecer a geração de renda nas mais variadas formas.

\section{Quanto ao coeficiente de elasticidade-renda do frango e à evolução econômica de Juazeiro do Norte}

No que se refere ao coeficiente de elasticidade-renda da demanda, obtidos de Silveira et al. (2007), a carne de frango é classificada economicamente como um bem normal, significando que para cada $1 \%$ de aumento que houver na renda do consumidor, haverá a tendência de um aumento de 1,5\% na demanda por carne de frango, se todos os outros os fatores que interferem nessa demanda se mantiverem inalterados no tempo (Tabela 1).

TABELA 1 - Coeficientes de elasticidade-renda da demanda $\left(E_{R}\right)$ de carne de frango.

\begin{tabular}{lc}
\hline Região Metropolitana & $E_{R}$ \\
\hline Fortaleza & 0,5560 \\
Recife & 0,5936 \\
Média & $\mathbf{0 , 5 7 4 8}$ \\
\hline
\end{tabular}

Fonte: Silveira et al. (2007). 
Assim, fazendo-se um breve raciocínio, utilizando o coeficiente de 0,57 mencionado acima e os $15,9 \mathrm{~kg}$ por habitante, o consumo anual médio de frango na Região Metropolitana de Fortaleza, de acordo com a última Pesquisa de Orçamentos Familiares (POF) realizada em 2008 pelo IBGE, esse consumo per capita aumentaria cerca de 725 gramas, caso o salário mínimo aumentasse $7,6 \%$, que é a média anual de aumento salarial no Brasil ocorrido entre 2010 e 2015.

Outro fato importante a ser considerado é que o aumento anual do salário mínimo não abrange todas as pessoas com renda no Brasil e sim, somente certa parcela da população, o que dificulta as estimativas reais para o consumo total de carne de frango na cidade em estudo como um todo, apesar da opinião de Silveira et al. (2007) de que a carne de frango se insere no grupo dos gêneros alimentícios considerados baratos e de consumo generalizado e de que sua aquisição não é influenciada pela renda.

Entretanto, diante do impacto que evidentemente o aumento populacional de uma cidade injeta em um determinado mercado alimentício e a variação que a renda dessa população causa na demanda agregada local, é de se supor que ocorra uma pressão de aumento na produção e na oferta do produto. Os 725 gramas estimados, no incremento do consumo de carne de frango por pessoa que poderia ocorrer causaria praticamente nenhum efeito na produção desse alimento caso esse acréscimo na renda ocorresse de forma muito pontual. Todavia, partindo-se de dados mais abrangentes e oficiais disponibilizados no site do IBGE referentes ao PIB ( $R$ \$ 2,3 bilhões em 2012) e à população (255.648 habitantes) de Juazeiro do Norte em 2012, chegou-se ao valor aproximado de $R \$ 9,0$ mil a renda per capita registrada para a cidade no referido ano.

Assim, considerando-se, por exemplo, a parcela da referida população que se encontrava naquele ano, na situação economicamente ativa, com renda de no máximo dois salários mínimos mensais (cerca de $35 \%$ da população total, ou seja, o equivalente a $89.476,8$ habitantes), o referido aumento de $7,6 \%$ no salário mínimo, tenderia a causar um aumento de, aproximadamente, 62 toneladas na demanda por frango na referida cidade. Ou seja, como consequência deveriam ser produzidos e ofertados cerca de 25 mil frangos a mais para atender somente essa parte da população local com essa nova renda, considerando um peso médio de 2,5 quilogramas por frango inteiro abatido. Fazendo a mesma análise, porém, considerando agora a população local estimada pelo IBGE para 2016 (268.248 habitantes), esse incremento na demanda aumentaria em cerca de 64 toneladas somente pela parcela da população com rendimentos mensais de até $R \$ 1.760,00$ (dois salários mínimo mensais).

Observa-se, assim, o grande impacto que uma leve variação no salário mínimo, como exemplo, pode trazer para o consumo de frangos de corte se fosse considerada toda a população consumidora dessa carne, inclusive com maiores rendimentos, tratando-se de um pequeno exemplo do grande potencial que não só a cidade de Juazeiro do Norte, mas em as cidades circunvizinhas. Vale salientar que, esses foram resultados considerando um aumento médio verificado anualmente no salário mínimo desde o ano de 2010, bem menor do que vinha sendo registrado anualmente com relação ao aumento da renda per capita local e, desconsiderando as imperfeições da economia, no que se refere à "divisão" do Produto Interno Bruto no atendimento das necessidades e da dimensão da população que se verifica, na verdade, em todo o Brasil. 
Entretanto, considerando o levantamento feito pela Associação Brasileira de Proteína Animal - ABPA (2015) em conjunto com a Associação Brasileira dos Produtores de Corte (APINCO), no qual foi apontado que o consumo médio de carne de frango per capita no Brasil foi de $42,78 \mathrm{~kg}$ em 2014 e tendo por base o montante de 92.296 habitantes a população economicamente ativa e com renda de no máximo dois salários mínimos mensais (35\% dos 263.704 habitantes de Juazeiro do Norte estimados para 2014), pode-se estimar que a demanda por frango na referida cidade foi de cerca de 4 mil toneladas, ou seja, o equivalente a 1,5 milhões de frangos, considerando um peso médio de 2,5 quilogramas por ave abatida (inteiro).

Nesse contexto, como descreve Queiroz (2014), o potencial dinâmico de Juazeiro do Norte pode ser explicado em grande parte pelo tamanho da aglomeração formada pela Região Metropolitana do Cariri, tendo os demais municípios integrantes dessa região como extensões complementares do potencial de consumo da mesma. Sendo assim, o potencial de consumo atendido pelo polo comercial de Juazeiro é, na verdade bem maior, levando-se em consideração a demanda dos municípios circunvizinhos.

Além disso, Queiroz (2014) também ressalta a grande diferença no que tange aos números anotados para os municípios mais dinâmicos da Região Metropolitana do Cariri, afirmando que nesse núcleo metropolitano, Juazeiro do Norte aparece em destacada posição no que se refere ao tamanho do seu contingente populacional. $O$ referido autor coloca Juazeiro como município-polo, que representa, sozinho, 44,3\% da população da região e isso evidencia o significativo poder de mercado local. Por outro lado, no período compreendido entre os anos de 2002 e 2014 o avanço econômico de Juazeiro do Norte é facilmente perceptível (Figura 2).

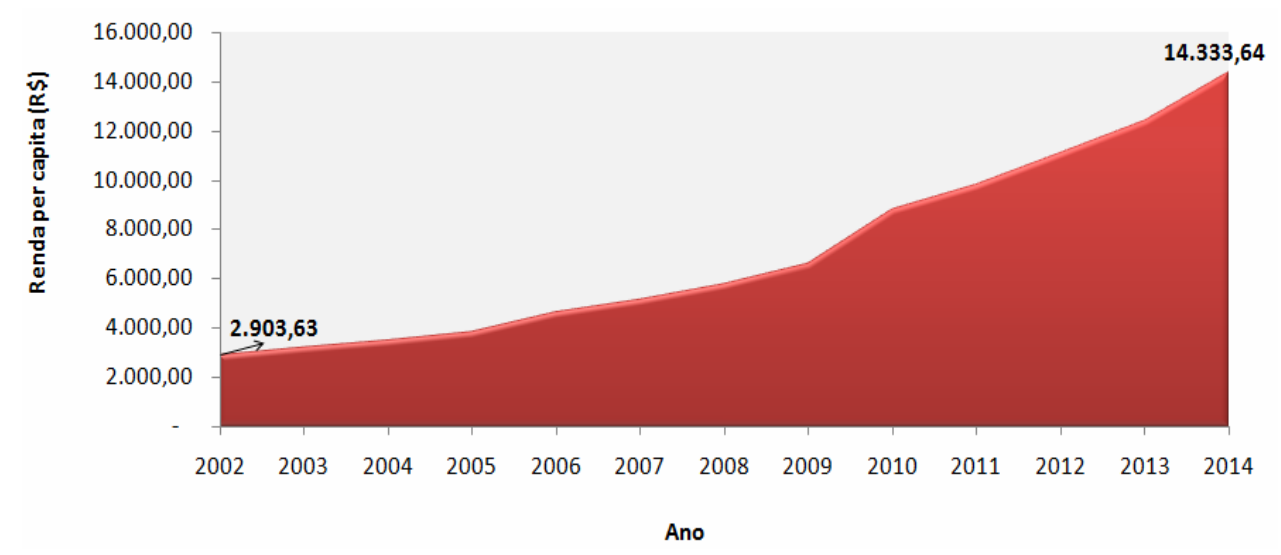

FIGURA 2 - Evolução da renda per capita da cidade de Juazeiro do Norte - CE. Fonte: Elaboração própria

Com os crescimentos do PIB (mais significativo) e da população (bem mais estável) verificados para Juazeiro do Norte, era de se esperar que a renda per capita do município realmente avançasse durante o período. De forma concreta, esse incremento médio foi de $14,4 \%$ ao ano, com o maior pico tendo ocorrido de 2009 para $2010(33,1 \%)$ e um pouco menos $(20,8 \%)$ de 2005 para 2006.

São percentuais que demonstram o grande crescimento econômico que ocorreu na cidade em um período somente de 12 anos, tratando-se de um fenômeno que geralmente causa fortes impactos locais na demanda por todo tipo de bens e serviços. Diante disso, além da demanda por bens finais, a demanda por bens 
intermediários também tenderia a aumentar, pois grande parte do crescimento econômico que envolve a referida região, deve-se ao aumento dos investimentos locais no comércio, na indústria e, consequentemente, na habitação e no setor imobiliário. É evidente que os índices relacionados aos investimentos locais comprovam a tendência crescente na economia local como um todo, ocasionando a evolução da renda média da população, que quando comparada com o aumento demográfico local, apresentou um expressivo aumento (Figura 3).

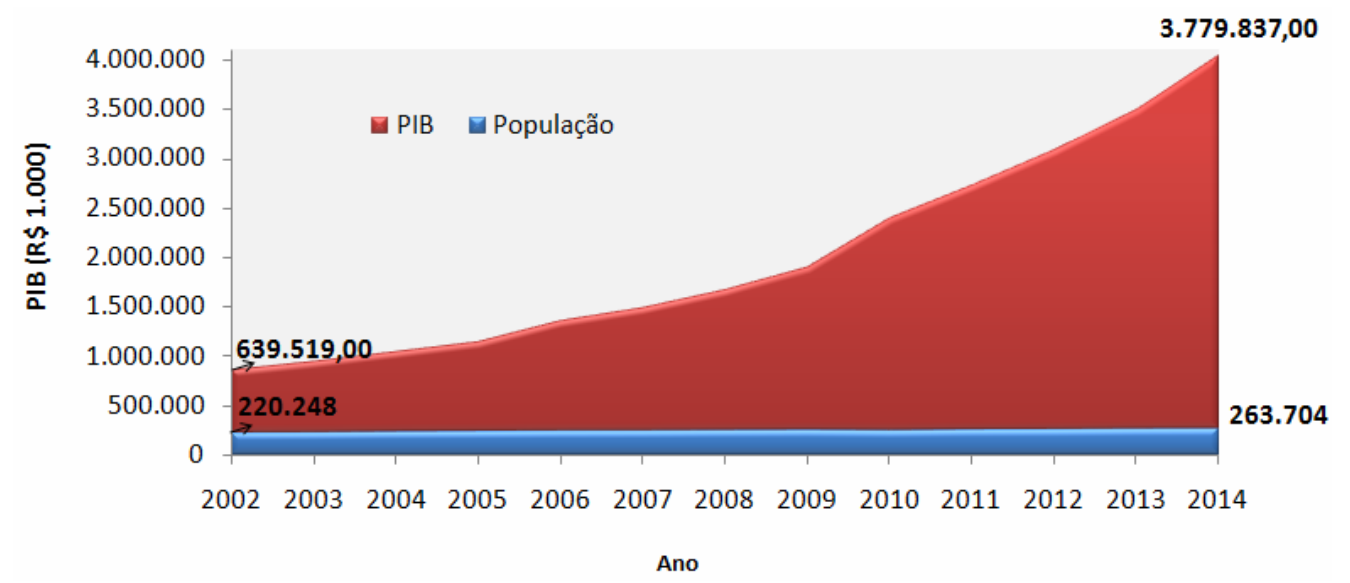

FIGURA 3 - Comparativo entre as evoluções demográfica e econômica do Fonte: Elaboração própria município de Juazeiro do Norte - CE.

Assim, diante das variáveis analisadas são apresentadas a seguir, a determinação da taxa de crescimento da demanda de carne de frango na região do Cariri. Sendo então:

- $P=1,5 \%$ (taxa média anual de crescimento demográfico da cidade de Juazeiro do Norte no período 2002-2014);

- $E=0,57$ (coeficiente de elasticidade-renda de frango, considerado);

- $G=14,4 \%$ (taxa média anual de crescimento da renda per capita da cidade de Juazeiro do Norte no período 2002-2014).

Portanto, a partir da fórmula utilizada para determinar a taxa média anual de crescimento da demanda por alimentos $(D=P+E G)$, tem-se que:

$$
D=1,5+0,57 \times(14,4) \quad \rightarrow \quad D=1,5+7,01 \quad \rightarrow \quad D=8,3 \% \text { ao ano }
$$

O resultado mostra que a demanda por carne de frango na cidade de Juazeiro do Norte pode ter crescido a um ritmo médio de $8,3 \%$ ao ano durante o período de 2002 a 2014, sendo 1,5\% devido à expansão demográfica e 7,01\% em função da aumento da renda per capita da referida cidade.

Enfatiza-se que o valor de $8,5 \%$ ao ano obtido trata-se de aproximação sujeita a erros, considerando a precisão dos dados das variáveis utilizadas (população e renda per capita de Juazeiro do Norte) e disponíveis no site do IBGE. Fatores como o grau de exatidão na contagem da população e na medição da renda média por habitante, essa sendo influenciada pela forte presença do serviço informal, ou seja, difícil de ser mensurável, bem como a utilização de coeficientes de elasticidade obtidos ainda em nível de Regiões Metropolitanas, podem contribuir para 
determinação um tanto quanto imprecisa das taxas de crescimento obtidas em locais mais específicos, como por cidade.

Diante disso, percebe-se que simulações poderiam ser feitas para se projetar vários cenários de demanda. A utilização de diferentes indicadores que permitam o conhecimento e o acompanhamento da evolução dos fatores que interferem de forma direta e indireta no crescimento demográfico (taxa de natalidade, taxa de mortalidade e migração) e na renda (taxa de emprego), bem como a taxa de ampliação da chegada de indústrias, por exemplo, podem ser bastante úteis em análises de correlações, com o intuito de se conhecer a real origem das variações da demanda pela população e acompanhar como esses fatores irão impactar no consumo. Além disso, as taxas de crescimento da demanda poderiam ser ainda mais exatas com a utilização de coeficientes de elasticidade-renda específicos para cada produto e para cada cidade.

Deve-se atentar novamente para o fato de que apesar da taxa de crescimento da demanda ter sido positiva, revelando tendência de aumento da procura por frango, a presente situação só considerou a evolução populacional e a evolução da renda local. Outros fatores que influenciam diretamente na procura e, consequentemente, no consumo de carne de frangos como gostos, preferências, qualidade, marcas etc. e, principalmente, a mudança cada vez mais rápida no padrão de consumo da sociedade, tendem a mudar a taxa obtida. Vários trabalhos evidenciam realmente que as decisões de consumo alimentar são influenciadas por diversas variáveis de caráter econômico e social, sendo a renda realmente uma dos principais parâmetros condicionantes na ingestão de carnes. Nesse contexto, estudos como o de Hoffmann (2000) tem avaliado como a variável renda influencia o consumo de carnes no Brasil.

Outra questão a ser observada trata-se das projeções existentes para a população de todo o Brasil para as próximas décadas. As análises do IBGE apontam decréscimos sucessivos nos índices diretamente relacionadas à evolução demográfica, como nascimentos e a taxa de fecundidade, inclusive com previsões de decréscimo da população brasileira a partir de 2050. Além disso, outras atividades realizadas pelo IBGE, como a Pesquisa de Orçamento Familiar (POF), já mencionada anteriormente, mostram poucas oscilações no consumo de carne de frangos e de seus subprodutos. Para a Região Metropolitana de Fortaleza, um dos centros consumidores mais próximos de Juazeiro do Norte com dados de consumo divulgados pelo IBGE, dos diferentes itens alimentícios oriundos do frango, somente o frango vivo possui dados de consumo em todas as quatro pesquisas de orçamento familiar realizadas até 0 momento. Nesse produto se percebem discretas diminuições na aquisição do mesmo, passando de mais de meio quilograma para somente cerca de setenta e oito gramas consumidas individualmente em média por ano, considerando todas as classes sociais juntas. Esse resultado é diferente quando se observam as classes de renda separadamente.

Deve-se ponderar que se tratam de valores obtidos junto a consumidores que levaram em consideração, além dos preços dos produtos e de suas rendas familiares, seus gostos, preferências e necessidades, ou seja, fatores que não são considerados de forma direta quando da utilização do procedimento matemático utilizado na presente pesquisa. Assim, percebe-se como primordial a necessidade da realização de estudos mais específicos, por produtos e por regiões, que possam levar em consideração as tendências de consumo e cultura da sociedade local. 
Análises de demanda e de oferta de alimentos produzidos no sistema orgânico e agroecológico, por exemplo, serão cada vez mais necessárias.

No que se refere às tendências, não se pode afirmar com exatidão como será o perfil de consumo de carne de frango no futuro, ainda mais quando se tem uma economia dinâmica e de forma integrada em todo o mundo, com as diferenças culturais e demais externalidades que influenciam diretamente na preferência do consumidor. Entretanto, podem-se fazer algumas projeções levando-se em consideração a forma como a população local aumentou e como a renda média dessa mesma população tem evoluído no decorrer dos anos (Tabela 4).

TABELA 4 - Expansões estimadas da demanda de carne de frango para Juazeiro do Norte - Ceará (ano base: 2017).

\begin{tabular}{ccc}
\hline Ano & Índice de demanda $(\mathrm{Vn})$ & Expansão acumulada (\%) \\
\hline 2017 & 100,00 & - \\
2018 & 108,30 & 8,3 \\
2019 & 117,29 & 17,3 \\
2020 & 127,02 & 27,0 \\
2021 & 137,57 & 37,6 \\
2022 & 148,98 & 49,0 \\
\hline
\end{tabular}

Fonte: Elaboração própria

Os índices de demanda obtidos permitem comparar o incremento absoluto de um ano com o ano antecedente, possibilitando a determinação do aumento percentual da demanda de cada ano futuro com relação ao ano de 2017, aqui considerado o ano base. O índice 117,29 obtido para 2019, por exemplo, significa que, se a procura por carne de frango continuar aumentando a um ritmo médio de $8,3 \%$ ao ano na cidade de Juazeiro do Norte, a demanda pelo referido alimento naquele ano será $17,29 \%$ maior do que a demanda ocorrida no ano de 2017 . Dessa forma, permanecendo nesse ritmo, poder-se-ia afirmar que até o ano de 2022 a demanda por esse produto na referida cidade tenderia a aumentar quase $50 \%$ comparando-se com o montante de demanda estimado para o alimento em 2017.

Mesmo com uma análise simples, pode-se perceber que qualquer aumento populacional, bem como qualquer elevação na renda dessa população tende a causar um forte impacto na procura por esse produto alimentício por se tratar de um item bastante acessível do ponto de vista comercial e nutricional, fazendo parte inclusive já da cultura brasileira consumir, principalmente aos domingos, o frango na forma assada, possibilitando o desenvolvimento de mais uma das várias formas de oferta do produto no mercado. Daqui a 10 anos, verifica-se que haverá a necessidade da oferta de frango no mínimo duas vezes maior do que se tem hoje no mercado da cidade de Juazeiro do Norte para atender a futura demanda local, causando impactos diretos em toda a cadeia de produção.

Nesse caso, a produção de milho e/ou de sorgo para a alimentação das aves nas futuras criações, por exemplo, poderá vir a ser um dos melhores investimentos na região, assim como a abertura de pontos comerciais que ofertem diferentes produtos voltados para a avicultura (rações, pintos, remédios, equipamentos etc.). Além disso, o estabelecimento cada vez maior tanto de unidades de criação como de lojas especializadas no setor tende a contribuir também mais para a geração de emprego e renda em toda a região. Esse fato favorece fluxo monetário mais intenso 
nos centros comerciais locais, que por sua vez proporcionam mais investimentos nos demais setores da economia, como no próprio setor imobiliário e nos setores privados educacionais, que consequentemente, trariam impactos, principalmente, na construção civil e nas escolas e nas unidades de ensino superior.

Um importante fator também a ser enfatizado é de que o desenvolvimento do mercado de frangos de corte com vistas a atender a significativa demanda em Juazeiro poderia ser bastante beneficiado pela presença atual de dois importantes centros de educação superior voltados para a pecuária de modo geral, o Instituto Federal de Educação, Ciência e Tecnologia do Ceará, IFCE - Campus Crato, com o seu curso de Bacharelado em Zootecnia e a Universidade Federal do Cariri, UFCA Campus Crato, com a Agronomia. Ambos os cursos podem contribuir diretamente para o desenvolvimento do setor com ensino e pesquisas que promovam, no final, a oferta de aves com qualidades sanitárias e nutricionais superioras.

É preciso atentar também que o incremento na demanda por carne de frango deve vir acompanhado de um forte estímulo à produção e à oferta do produto de modo a contribuir para a diminuição dos preços de venda nos mais variados postos de comercio da cidade e de seu entorno. Considerando a forte tendência de procura para os próximos anos, constata-se que se não houver ações que promovam o aumento da produção local, a oferta que se tem hoje não será suficiente, o que poderá gerar elevação nos preços tanto do frango inteiro como de seus subprodutos.

A estimativa baseada nas taxas de crescimento da demanda obtidas para 0 frango será mais precisamente diagnosticada se for relacionada com outras variáveis além da evolução demográfica e do crescimento da renda per capita. Nesse caso, a determinação dos coeficientes de elastidade-preço da demanda e de elasticidade-cruzada da demanda dos diferentes tipos de carnes e para o Cariri, poderiam ajudar nesse sentido, pois associariam outros fatores que afetam nono consumo como os preços e as preferências dos diferentes itens. O que ocorre é que a dificuldade em obter dados precisos acerca da evolução da renda da população, principalmente, em cidades menores do que os grandes centros urbanos é um obstáculo para mensurações mais refinadas.

De qualquer forma, simulações podem ser realizadas com alguns dados disponíveis, apesar das limitações das informações. A partir da Tabela 5 algumas observações são apresentadas nesse sentido, no intuito de discutir possíveis impactos no consumo de carne de frango a partir de certas condições de evolução socioeconômica.

TABELA 5 - Projeções estimadas para o consumo de carne de frango para Juazeiro do Norte - Ceará, com base na evolução demográfica local (ano base: 2017).

\begin{tabular}{cccccc}
\hline Ano & $\begin{array}{c}\text { População } \\
\text { estimada } \\
(\mathrm{P})\end{array}$ & $\begin{array}{c}\text { Consumo } \\
\text { estimado } \\
\text { (ton.) } \\
\left(\mathrm{P} \times 42,78^{*}\right)\end{array}$ & $\begin{array}{c}\text { Aumento } \\
\text { estimado do } \\
\text { consumo } \\
\text { (ton./ano) }\end{array}$ & $\begin{array}{c}\text { Número de } \\
\text { frangos a } \\
\text { serem } \\
\text { ofertados }\end{array}$ & $\begin{array}{c}\text { Aumento } \\
\text { estimado na } \\
\text { oferta } \\
\text { (frangos/ano) }\end{array}$ \\
\hline 2017 & 271.674 & 11.394 & - & 4.557 .603 & - \\
2018 & 275.749 & 11.565 & 171 & 4.625 .967 & 68.364 \\
2019 & 279.885 & 11.738 & 173 & 4.695 .357 & 69.390 \\
2020 & 284.084 & 11.914 & 176 & 4.765 .787 & 70.430 \\
2021 & 288.345 & 12.093 & 179 & 4.837 .274 & 71.487 \\
2022 & 292.670 & 12.275 & 181 & 4.909 .833 & 72.559 \\
\hline \multicolumn{5}{r}{ Fonte: Elaboração própria, a partir de IBGE (2017) } & * Consumo médio de frango ABPA (2015)
\end{tabular}


Considerando-se que haja as continuidade de 1,5\% na evolução demográfica e do consumo médio anual de 41,94 kg de frango por pessoa, um aumento de quase 21 mil habitantes em Juazeiro do Norte no período 2017-2022 tenderá a causar um acréscimo de 880 toneladas na demanda pelo referido alimento, sendo então necessário a adição de mais de 352 mil frangos somente nesse período de cinco anos no mercado local, ou seja, um média de 70,4 mil cabeças a mais a cada ano.

O mesmo raciocínio pode ser feito também considerando a evolução demográfica da parcela da população de Juazeiro do Norte com renda de até dois salários mínimos mensais, parcela essa que na verdade vinha representando, segundo os dados oficiais do IBGE, mais de $87 \%$ da população brasileira em todo o Brasil. Assim, considerando-se a mesma taxa percentual na evolução demográfica, no entanto, na referida faixa de renda, bem como o mesmo consumo médio anual per capita, o aumento proporcional do número de habitantes locais com a referida renda tenderá a causar um acréscimo de 429 toneladas no consumo de carne de frango, sendo assim necessário o acrescentamento de mais de 171 mil frangos durante o mesmo período no mercado juazeirense (Tabela 6).

TABELA 6 - Projeções estimadas para o consumo de carne de frango para Juazeiro do Norte - Ceará, com base na evolução do salário mínimo (ano base: 2017).

\begin{tabular}{cccc}
\hline Ano & $\begin{array}{c}\text { Consumo estimado (ton.) } \\
\text { (Até 2 salários mínimos) }\end{array}$ & $\begin{array}{c}\text { Aumento estimado do } \\
\text { consumo (ton./ano) }\end{array}$ & $\begin{array}{c}\text { Número de frangos } \\
\text { para serem } \\
\text { ofertados }\end{array}$ \\
\hline 2017 & 5.603 & - & 2.241 .156 \\
2018 & 5.687 & 84,05 & 2.274 .775 \\
2019 & 5.768 & 81,18 & 2.307 .246 \\
2020 & 5.855 & 86,50 & 2.341 .847 \\
2021 & 5.942 & 87,84 & 2.376 .984 \\
2022 & 6.032 & 89,14 & 2.412 .641 \\
\hline
\end{tabular}

Fonte: Elaboração própria, a partir de dados do IBGE (2017)

Os valores acima, apesar de representarem simulações a partir de alguns dados que demonstram a forma como a economia e suas consequências evoluíram em anos anteriores, podem dar um ideia da tendência das necessidades que as pessoas passam a ter em decorrência de melhoria de alguns dos vários fatores que interferem na demanda pelos bens e serviços. O aumento populacional, por si só, resultante da mudança de fatores econômicos e/ou sociais, independentemente do grau com que ocorra, certamente gera certa pressão na produção de bens e serviços e, consequentemente, produz outros tipos demanda por bens e serviços intermediários, estes muitas vezes considerados como recursos para a obtenção dos bens e serviços finais. Esse fluxo de necessidades por sua vez demanda do mercado uma estrutura diversificada nos âmbitos público e privado, que quando é compreendida e construída com um eficiente processo de planejamento, traz consigo um sistema de retroalimentação físico-monetária onde tende a trazer diferentes formas de benefícios para a sociedade e o sistema agroalimentar se insere perfeitamente nesse contexto.

As características do Brasil no setor emprego e trabalho, onde a presença de serviços informais, de difícil mensuração, torna o conhecimento das tendências a partir de taxas de crescimento mais complicado de ser obtido. Mesmo assim, ainda 
será umas das mais simples e ao mesmo tempo boas formas de se fazer projeções de consumo, pois permite uma rápida utilização e análise de dados a partir de um sistema com boas tendências de melhoria que é a base estatística brasileira.

\section{CONCLUÕES}

Conclui-se que a demanda por carne de frango na cidade de Juazeiro do Norte aumentará basicamente em função da evolução do valor da produção local, com a influência da evolução de demográfica muito pequena nesse sentido. O nível com que esse crescimento da demanda ocorrerá dependerá do grau com que as políticas econômicas brasileiras influenciarão nos investimentos e como estes implicarão da geração de postos de trabalho.

A crescente variedade cultural da população juazeirense, também diretamente relacionada à evolução econômica, deve motivar a maior oferta de subprodutos da carne frango, nas formas fresca e congelada; e essa maior procura tende a contribuir ainda mais para o desenvolvimento do setor, a partir do aumento do número de criatórios nas imediações da cidade.

Os maiores investimentos locais realizados, motivados, principalmente, pelo avanço do turismo religioso, também tendem a contribuir para o aumento da demanda e da oferta por carne de frango, pela praticidade de preparo, sabor e aceitação de consumo do referido item nos mais variados tipos de estabelecimentos comerciais ligados à alimentação local.

\section{REFERENCIAS}

ABPA. Associação Brasileira de Proteína Animal. Artigos. Coletiva da ABPA: Números e previsões para a avicultura e a suinocultura em 2016. Disponível em: <http://abpa-br.com.br/noticia/coletiva-da-abpa-numeros-e-previsoes-para-aavicultura-e-a-suinocultura-em-2016-1907>. Acesso em: 22 ago. 2017.

CARBONARI, T.; SILVA, C. R. L. D. Estimativa da elasticidade-renda do consumo de carnes no Brasil empregando dados em painel. Pesquisa e Debate, São Paulo, v. 23, $\quad$ n. $1, \quad$ p. $154-178, \quad 2012 . \quad$ URL: https://revistas.pucsp.br/index.php/rpe/article/view/12383

\section{DIÁRIO DO NORDESTE. Negócios. Cariri é o maior polo calçadista do Nordeste. $2011 . \quad$ Disponível em:} <http://diariodonordeste.verdesmares.com.br/cadernos/negocios/cariri-e-o-maiorpolo-calcadista-do-nordeste-1.315364>. Acesso em 20 ago. 2017.

\section{GLOBO RURAL. Consumo per capita de carnes no Brasil é o menor em oito} anos. Disponível em: <http://revistagloborural.globo.com/Noticias/Criacao/noticia/2017/07/consumo-capitade-carnes-no-brasil-e-o-menor-em-oito-anos.html>. Acesso em 10 ago. 2017.

HOFFMANN, R. Análise de regressão: uma introdução à econometria [recurso eletrônico]. Piracicaba: ESALQ/USP, 2015. 393 p.

HOFFMANN, R. Elasticidades-renda das despesas com alimentos em regiões metropolitanas do Brasil em 1995-96. Informações Econômicas, SP, v. 30, n. 2, fev. 2000. URL: http://www.iea.sp.gov.br/ftpiea/ie/2000/tec2-fev2000.pdf 
HOFFMANN, R; SERRANO, O; NEVES, E.M.; THAME, A. C. M.; ENGLER, J. J. de Camargo. Administração da empresa agrícola. $7^{\text {ạ }}$ ed. São Paulo: Pioneira, 1992. $523 p$.

IBGE. Instituto Brasileiro de Geografia e Estatística. Censo Demográfico e Contagem da População. Disponível em: $<$ http://www.sidra.ibge.gov.br/bda/tabela/listabl.asp?z=cd\&o=2\&i=P\&c=616>. Acesso em: 22 abr. 2017.

Disponível

Instituto Brasileiro de Geografia e Estatística. Estimativas de População. em:<http://www.ibge.gov.br/home/estatistica/populacao/estimativa2016/estimativa_d ou.shtm>. Acesso em: 01 jun. 2017.

Instituto Brasileiro de Geografia e Estatística. Produto Interno Bruto dos Municípios $1999 \quad$ - 2013.2 Disponível em: <http://www.sidra.ibge.gov.br/bda/tabela/listabl.asp?z=p\&o=32\&i=P\&c=5938>. Acesso em: 20 mai. 2017.

Instituto Brasileiro de Geografia e Estatística. Pesquisa de orçamentos familiares $2008 \quad$ - 2009.2 Disponível em: < http://www.sidra.ibge.gov.br/bda/tabela/listabl.asp?z=p\&o=13\&c=419>. Acesso em: 30 jul. 2017.

IPECE. Instituto de Pesquisa e Estratégia Econômica do Ceará. Anuário Estatístico do Ceará 2015. Índice de Desenvolvimento Humano. Disponível em: $<$ http://www2.ipece.ce.gov.br/publicacoes/anuario/anuario2015/qualidade/indices/idh. htm>. Acesso em: 20 ago. 2017.

MAPA. Ministério da Agricultura, Pecuária e Abastecimento. Projeções do Agronegócio. Brasil 2016/17 a 2026/27. Projeções de Longo Prazo. Disponível em: < http://www.agricultura.gov.br/assuntos/politica-agricola/todas-publicacoes-depolitica-agricola/projecoes-do-agronegocio/projecoes-do-agronegocio-2017-a-2027versao-preliminar-25-07-17.pdf/view>. Acesso em: 25 set. 2017.

MIRANDA, H; GOMES-JÚNIOR, E. Urbanização reflexa: A emergência de arranjos urbanos intermediários no Brasil pós-1990. EURE, Revista Latinoamericana de Estudios Urbano Regionales, v. 43, n. 130, p. 207-234, 2017. DOI: http://dx.doi.org/10.4067/s0250-71612017000300207.

URL:http://www.scielo.cl/scielo.php?script=sci_arttext\&pid=S0250-

$71612017000300207 \&$ Ing=en\&nrm=iso

QUEIROZ, I. S. Região Metropolitana do Cariri Cearense: A metrópole fora do eixo. Mercator. Fortaleza. v. 13, n. 3, p. 93-104, set./dez. 2014. DOI: 10.4215/RM2014.1303. 0007

URL:

http://www.mercator.ufc.br/mercator/issue/view/RMv13n3 
SILVEIRA, F. G.; MAGALHÃES, L. C. G.; MeneZeS, T. A.; DINIZ, B. P. C. Elasticidade-renda dos produtos alimentares nas regiões metropolitanas brasileiras: uma aplicação da POF 1995/1996. Estudos Econômicos, v. 37, n.2, São Paulo, abr./jun. 2007. Disponível em: <http://www.scielo.br/scielo>. Acesso em: 28 out. 2016.

VARIAN, H. R. Microeconomia: uma abordagem moderna. Tradução Regina Célia Simile de Macedo. 9. Ed. Rio de Janeiro: Elsevier, 2016. 